\title{
Influence of pelvic osteotomy on birth canal size
}

\author{
R.T. Loder ${ }^{1}$, L.A.Karol ${ }^{1}$, and S. Johnson ${ }^{2}$ \\ ${ }^{1}$ Department of Orthopaedics and ${ }^{2}$ Department of Radiology, School of Medicine, Wayne State University, Detroit, Michigan, USA
}

Summary. Six pelvic osteotomies (Salter, Sutherland, Steel, Tönnis, Chiari, and periacetabular) were performed on the right hemipelvis of adult female pelvic plastic models. Each pelvis underwent conventional X-ray and computed tomographic digital pelvimetry before and after osteotomy. The change in the anteroposterior and transverse dimensions at the inlet, midpelvis, and outlet were calculated. None of the osteotomies significantly decreased the inlet. The Salter and Sutherland osteotomies decreased the midpelvis to borderline low. The Salter, Sutherland, and Steel osteotomies significantly decreased the pelvic outlet. These changes correlated closely with those in living patients. Much of this decrease is nullified when the osteotomy is performed prior to the pubertal growth spurt.

Pelvic osteotomy is most commonly performed in females for residual acetabular dysplasia. Knowing the effects of pelvic osteotomy on birth canal size could be useful in counselling female patients who have earlier undergone a pelvic osteotomy and have now reached reproductive age. It was the purpose of this study to investigate further the effect of pelvic osteotomy on birth canal size. Only one previous study has addressed this problem [21].

\section{Materials and methods}

Six gynecoid adult plastic pelvis model (Candent, P. O. Box 81, Toronto, Ontario, M6S 4T2 Canada) were subjected to obstetrical pelvimetry (S.J.) using both conventional and digital computed tomographic (CT) scan methods. Conventional pelvimetry uses anteroposterior and lateral radiographs [3]. Digital CT scan pelvimetry $[5,11]$ uses anteroposterior and lateral $\mathrm{CT}$ scan scout radiographs to obtain digital measurements. CT has replaced conventional pelvimetry because of its ease, speed, and reduced radiation [7]. Six standard pelvimetry measurements were made: the anteroposterior and transverse diameters at the inlet, midpelvis, and outlet levels [3] as shown in Fig. 1.

Correspondence to: Randall T.Loder, M.D., Section of Orthopaedics, University of Michigan Hospitals, 1500 East Medical Center Drive, TC 2912 G, Box 0328, Ann Arbor, MI 48109-0328, USA
An osteotomy as originally described was performed on each right hemipelvis. The osteotomies were the single innominate [16], double innominate [18] (25), triple innominate of Steel [17] and Tönnis [19], Chiari [2], and periacetabular [6]. After osteotomy, pelvimetry was again performed, and birth canal changes analyzed using two methods.

The first method calculates the sum of the transverse and anteroposterior diameters at each level. The theoretical effect of each osteotomy on an average female pelvis (Fig. 1) was calculated using the percentage change from our data. This compensated for anatomic variability in the models, allowing for an accurate comparison of changes solely from the osteotomy. The second method obtains an area equal to the product of anteroposterior and transverse diameters [12]. From Mengert's experience [12], 85\% of the average area represented borderline adequate pelvic capacity. We arbitrarily considered an area less than $80 \%$ of the average to be significantly decreased.

Transverse pelvic diameters in 11 female osteotomy patients were compared to our experimental results. (To have obtained anteroposterior diameters, either lateral radiographs or CT digital pelvimetry would be required. Although scientifically interesting, neither of these studies are clinically necessary to follow the osteotomy patient. Therefore, we could not, under ethical considerations, obtain them).

For eight patients we could determine the amount of bony remodeling that occurred after osteotomy. Remodeling occurs by natural physical growth during adolescence and there may also be stress-related remodeling according to Wolff's law, even in patients without open physes. The amount of remodeling was analyzed differently for skeletally immature and skeletally mature patients. For those where the follow-up time span included the pubertal growth spurt, the final follow-up pelvic dimensions were compared to the adult norms used in this study. For those where the osteotomy was done after adolescence, the final follow-up pelvic dimensions were compared to the preoperative dimensions, since there is little increase in size and no change in pelvic shape in early adulthood after pubertal pelvic remodeling [8].

An in vitro adult plastic pelvis model is dissimilar from a pediatric in vivo pelvis, but is similar to a postpubescent pelvis. We felt this was the closest model available. Pediatric cadavers are scare and adult cadavers have serious drawbacks. Osteotomies hinge on soft tissue, which are stiff in cadavers, lessening the amount of acetabular reorientation that would be achieved. Elderly cadaver specimens are osteopenic, fracture easily and hold fixation poorly.

\section{Results}

The variability between conventional and CT digital pelvimetry diameters averaged $3 \mathrm{~mm}$. The percentage changes 


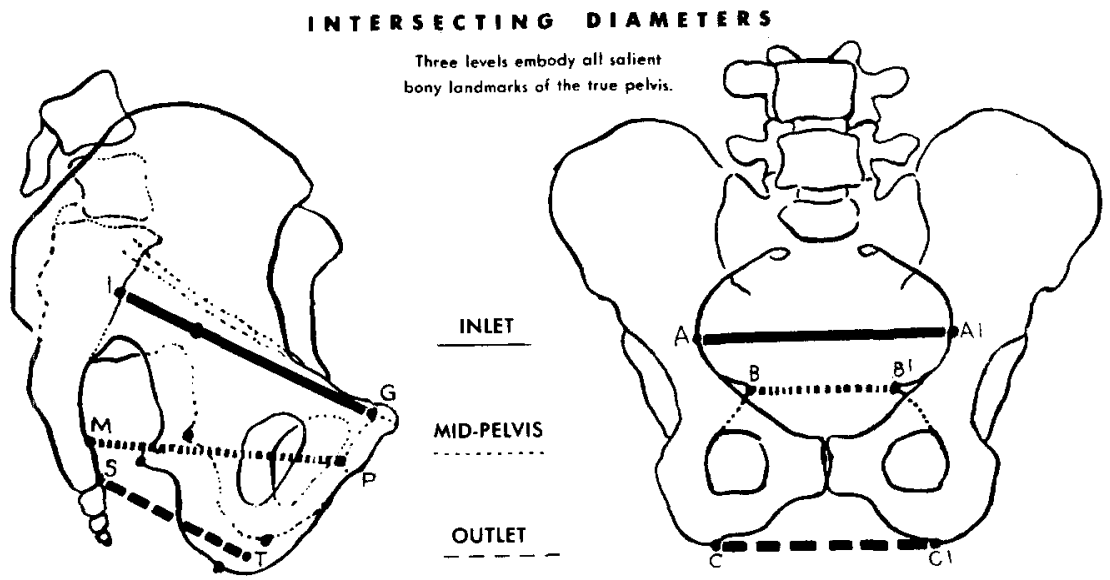

\begin{tabular}{|c|c|c|c|c|c|c|}
\hline \multicolumn{3}{|c|}{ DIAMETERS } & TOTAL & $\begin{array}{l}\text { AVERAGE } \\
\text { NORMAL }\end{array}$ & $\begin{array}{l}\text { AVERAGE } \\
\text { TOTAL }\end{array}$ & $\begin{array}{c}\text { LOW } \\
\text { NORMAL }\end{array}$ \\
\hline ACTUAL INLET & $\begin{array}{l}\text { Anteroposterior } \\
\text { Tronsverse }\end{array}$ & $\begin{array}{l}1 \text { to } G \\
\text { A to } A 1\end{array}$ & & $\begin{array}{l}12.5 \\
13.0\end{array}$ & 25.5 & 22.0 \\
\hline MID-PELVIS & $\begin{array}{l}\text { Anteroposterior } \\
\text { Transverse (Bispinous) }\end{array}$ & $\begin{array}{l}M \text { to } P \\
B \text { to } B \text { 1 }\end{array}$ & & $\begin{array}{l}11.5 \\
10.5\end{array}$ & 22.0 & 20.0 \\
\hline OUTLET & $\begin{array}{l}\text { Anteroposterior (Post. Sagittal) } \\
\text { Transverse (Bituberal) }\end{array}$ & $\begin{array}{l}S \text { to } \mathrm{T} \\
\mathrm{C} \text { to } \mathrm{Cl}^{-1}\end{array}$ & & $\begin{array}{r}7.5 \\
10.5\end{array}$ & 18.0 & 16.0 \\
\hline
\end{tabular}

Fig. 1. Diameters used in obstetrical pelvimetry with standard values (in $\mathrm{cm}$ ). (Reproduced by permission, Picker International, Inc.)
Table 1. Changes in pelvic dimensions (\%) after experimental osteotomy

\begin{tabular}{|c|c|c|c|c|c|c|}
\hline Diameters & Salter & $\begin{array}{l}\text { Suther- } \\
\text { land }\end{array}$ & Steel & Chiari & Tönnis & Periacetabular \\
\hline \multicolumn{7}{|c|}{ Conventional pelvimetry } \\
\hline Inlet AP & -2 & -5 & +4 & +7 & -3 & -2 \\
\hline Transverse & +4 & -2 & +2 & -16 & +5 & +3 \\
\hline Total & +1 & -4 & +3 & -5 & +1 & +2 \\
\hline Midpelvis AP & -13 & +5 & +6 & +3 & 0 & +18 \\
\hline Transverse & -5 & -19 & -15 & -15 & -5 & -2 \\
\hline Total & -9 & -6 & -4 & -6 & -2 & -8 \\
\hline Outlet AP & -37 & -21 & -9 & -8 & -18 & -1 \\
\hline Transverse & -17 & -29 & -16 & -8 & -3 & -1 \\
\hline Total & -25 & -26 & -13 & -8 & -10 & -1 \\
\hline \multicolumn{7}{|c|}{ CT digital pelvimetry. } \\
\hline Inlet $\mathrm{AP}$ & 0 & -1 & +4 & +2 & -2 & 0 \\
\hline Transverse & 0 & -2 & 0 & -13 & 0 & +1 \\
\hline Total & 0 & -2 & +2 & -7 & -1 & 0 \\
\hline Midpelvis AP & -12 & +3 & +4 & +6 & -1 & +7 \\
\hline Transverse & -12 & -24 & -19 & -16 & -7 & -2 \\
\hline Total & -12 & -11 & -8 & -5 & -4 & +2 \\
\hline Outlet AP & -27 & -17 & -9 & -5 & -17 & -11 \\
\hline Transverse & -20 & -30 & -22 & -7 & -2 & -1 \\
\hline Total & -23 & -25 & -17 & -6 & -8 & -15 \\
\hline
\end{tabular}

AP, Anteroposterior

are shown in Table 1, the theoretical effect of each osteotomy on an average female pelvis in Table 2 , and pelvic capacities in Table 3 . When both methods of pelvimetry and analysis were combined, no influence of any of the osteotomies was shown on the pelvic inlet. The Salter and Sutherland osteotomies decreased the midpelvic di- mensions to borderline low. The Salter, Sutherland, and Steel osteotomies decreased the pelvic outlet significantly.

The changes in patients' transverse diameters (Table 4) were similar to those of the plastic models. The average of the four unilateral Salter osteotomy patients was $+3 \%,-9 \%$ and $-14 \%$ for the inlet, midpelvis, and out- 
Table 2. Theoretical effect of pelvic osteotomy on the average female pelvis

\begin{tabular}{llll}
\hline Osteotomy type & $\begin{array}{l}\text { Total } \\
\text { measurement }\end{array}$ & \multicolumn{2}{l}{$\begin{array}{l}\text { Postosteotomy } \\
\text { measurements }\end{array}$} \\
\cline { 2 - 3 } Salter & & X-ray $(\mathrm{cm})$ & CT $(\mathrm{cm})$ \\
\hline & Inlet & 25.8 & 25.5 \\
& Midpelvis & 20.0 & $19.4^{\mathrm{a}}$ \\
Sutherland & Outlet & $13.6^{\mathrm{a}}$ & $13.9^{\mathrm{a}}$ \\
& Inlet & 24.6 & 25.1 \\
& Midpelvis & 20.7 & $19.7^{\mathrm{a}}$ \\
Steel & Outlet & $13.4^{\mathrm{a}}$ & $13.6^{\mathrm{a}}$ \\
& Inlet & 26.3 & 26.0 \\
& Midpelvis & 21.1 & 20.3 \\
Chiari & Outlet & $15.7^{\mathrm{a}}$ & $15.0^{\mathrm{a}}$ \\
& Inlet & 24.2 & 23.8 \\
& Midpelvis & 20.7 & 20.9 \\
Tönnis & Outlet & 16.5 & 16.9 \\
& Inlet & 25.8 & 25.3 \\
& Midpelvis & 21.5 & 21.1 \\
& Outlet & 16.3 & 16.6 \\
& Inlet & 25.9 & 25.6 \\
& Midpelvis & 23.8 & 22.5 \\
& Outlet & 17.8 & 17.2 \\
\hline
\end{tabular}

a Postosteotomy measurements below the low normal threshold, using the norms from Fig. 1

let diameters respectively. These changes were comparable to the $+4 \%,-5 \%$ and $-17 \%$ noted in the experimental model. The averages for the two unilateral Steel osteotomies, the single Sutherland osteotomy, and the three unilateral Chiari osteotomies were also similar to the models. These changes remodeled when the osteotomies were performed prior to the pubertal growth spurt (Table 4 , patients $2,7,8,11$ ), but minimally so after the pubertal growth spurt (Table 4, patients 1, 9, $10)$.

\section{Discussion}

Many factors should be considered in selecting a pelvic osteotomy. These include the ability to do a redirectional osteotomy (e.g., Salter, Sutherland, Steel, Tönnis, or periacetabular) if the hip joint is or can be made congruous, versus a salvage osteotomy (e.g., Chiari). Other factors include the amount of acetabular coverage needed, and the potential for further acetabular remodeling prior to skeletal maturity. The presence of an open triradiate cartilage contraindicates certain osteotomies (e.g., periacetabular). The surgeon's technical ability, experience, and comfort in performing a proposed osteotomy are also important. We believe that these factors (especially the surgeon's technical ability) are more important determinants in choosing an osteotomy than the theoretical effect on birth canal size. The results of this study should be cautiously used in the decision-making process.

Only one previous study has addressed the influence of pelvic osteotomy on birth canal size. Winkelman [21] used cadaver pelves, pelvis models, and patient examples. The Chiari, Salter, and Sutherland osteotomies narrowed the pelvic transverse outlet diameter (which he termed the "intertuber-ischial" diameter) of up to 3,1, and $3.5 \mathrm{~cm}$ for each osteotomy respectively. The Chiari osteotomy decreased the transverse diameter of the pelvic brim (inlet), and the Steel and Tönnis osteotomies narrowed the middle part of the bony canal. He did not define the middle part of the bony canal, but it is most likely the midpelvis area as defined in this study. Winkelman did not study the anteroposterior diameter changes, nor determine what might be a decrease below the normal pelvic size.

In this study, none of the osteotomies decreased the pelvic inlet, the Salter and Sutherland osteotomies caused a borderline decrease in the midpelvis, and the outlet was significantly narrowed by the Salter, Sutherland, and Steel osteotomies. There are many factors which may modify these changes in the living patient. The first is remodeling, which may partly restore the pelvis to normal size, especially if the osteotomy is performed before physeal closure. In eight skeletally immature patients we noted considerable remodeling (often to normal diameters) after the Chiari, Salter, Steel, and Sutherland osteotomies. The Salter and Chiari osteotomies in this study were followed by no remodeling when performed after skeletal maturity, although Winkelman [21] noted remodeling in a skeletally mature patient after bilateral Chiari osteotomies.

Second, the amount of acetabular reorientation achieved experimentally may not be achieved clinically because of soft tissue constraints. However, we attempted to per-
Table 3. Changes in pelvic capacity (Mengert areas) (\%) after experimental osteotomy

\begin{tabular}{lrrrrrr}
\hline & Salter & $\begin{array}{l}\text { Suther- } \\
\text { land }\end{array}$ & Steel & Chiari & Tönnis & Periacetabular \\
\hline Conventional pelvimetry & & & & & & \\
$\quad$ Inlet & +2 & -7 & +7 & -10 & +2 & +1 \\
Midpelvis & -17 & -15 & -9 & -13 & -4 & +15 \\
$\quad$ Outlet & -47 & -43 & -35 & -15 & -19 & -3 \\
CT digital pelvimetry & & & & & & \\
Inlet & 0 & -3 & +4 & -12 & -2 & +1 \\
Midpelvis & -12 & -22 & -16 & -11 & -8 & 0 \\
$\quad$ Outlet & -41 & -42 & -28 & -13 & -18 & -11 \\
\hline
\end{tabular}


Table 4. Effects of pelvic osteotomy on transverse pelvic diameter in living female patients

\begin{tabular}{|c|c|c|c|c|c|}
\hline \multirow[t]{2}{*}{ Osteotomy } & \multirow[t]{2}{*}{$\begin{array}{l}\text { Patient } \\
\text { no. }{ }^{a}\end{array}$} & \multirow[t]{2}{*}{$\begin{array}{l}\text { Patient age } \\
\text { (years: months) }\end{array}$} & \multicolumn{3}{|c|}{$\begin{array}{l}\text { Transverse pelvic diameter changes } \\
(\%)\end{array}$} \\
\hline & & & Inlet & Midpelvis & Outlet \\
\hline \multirow[t]{4}{*}{ Salter } & 1 & $\begin{array}{l}48 \mathrm{f} / \mathrm{u} \\
\text { (osteotomy } \\
\text { at age } 39 \text { ) }\end{array}$ & +3 & -4 & -11 \\
\hline & 2 & $\begin{array}{l}2: 3 \\
\text { (bilateral) } \\
5: 3 \mathrm{f} / \mathrm{u}\end{array}$ & $\begin{array}{l}-7 \\
-2\end{array}$ & -11 & $\begin{array}{l}-27 \\
-23\end{array}$ \\
\hline & 3 & $1: 10$ & 0 & -10 & -23 \\
\hline & $\begin{array}{l}4 \\
5\end{array}$ & $\begin{array}{l}2: 8 \\
3: 8 \\
15: 2 f / u^{b}\end{array}$ & $\begin{array}{r}-3 \\
+10 \\
+4\end{array}$ & $\begin{array}{r}-16 \\
-4 \\
+13\end{array}$ & $\begin{array}{r}-14 \\
-9 \\
0\end{array}$ \\
\hline \multirow[t]{2}{*}{ Steel } & 6 & $8: 2$ & -2 & -20 & -19 \\
\hline & 7 & $\begin{array}{l}14: 5 \\
18: 6 \mathrm{f} / \mathrm{u}^{\mathrm{b}}\end{array}$ & $\begin{array}{r}0 \\
+1\end{array}$ & $\begin{array}{r}-10 \\
-7\end{array}$ & $\begin{array}{r}-15 \\
-2\end{array}$ \\
\hline Sutherland & 8 & $\begin{array}{l}13: 8 \\
15: 7 \mathrm{f} / \mathrm{u}^{\mathrm{b}}\end{array}$ & $\begin{array}{l}-2 \\
+4\end{array}$ & $\begin{array}{l}-17 \\
-10\end{array}$ & $\begin{array}{l}-26 \\
-12\end{array}$ \\
\hline \multirow[t]{3}{*}{ Chiari } & 9 & $\begin{array}{l}16 \\
20 \mathrm{f} / \mathrm{u}\end{array}$ & $\begin{array}{r}-15 \\
-9\end{array}$ & $\begin{array}{l}-15 \\
-10\end{array}$ & $\begin{array}{r}-9 \\
0\end{array}$ \\
\hline & 10 & $\begin{array}{l}37 \\
44 \mathrm{f} / \mathrm{u}\end{array}$ & $\begin{array}{l}-12 \\
-10\end{array}$ & $\begin{array}{l}-14 \\
-16\end{array}$ & $\begin{array}{l}-8 \\
-8\end{array}$ \\
\hline & 11 & $\begin{array}{l}12: 8 \\
15: 2 \mathrm{f} / \mathrm{u}^{b}\end{array}$ & $\begin{array}{r}-14 \\
+4\end{array}$ & $\begin{array}{r}-16 \\
+2\end{array}$ & $\begin{array}{l}-10 \\
+10\end{array}$ \\
\hline
\end{tabular}

f/u, Àt follow-up

${ }^{a}$ Patient 1 from [21], Fig. 11; patient 2 from [16], case 4; patients 3-8, 11 contributed by various pediatric orthopedic surgeons; patients 9, 10 from [4], Figs. 3 (patient 9) and 2 (patient 10)

$\mathrm{b}$ Because of the large amount of pelvic growth seen during follow-up, the final follow-up diameters were compared to the adult norms used in this study form the osteotomies to simulate the in vivo situation. This is supported by the similarity between the clinical and experimental data (Table 4).

Third, the type of pelvis might modify these changes. Of the four main pelvis types, (gynecoid, android, platypelloid, and anthropoid [1]), the gynecoid pelvis is the normal female type, occurs in over $40 \%$ of women, and is ideal for childbirth. The incidence of operative delivery (forceps or cesarean section) is increased in women with the nongynecoid types of pelvis [14]. The changes after osteotomy may have a greater significance in a nongynecoid pelvis.

This study has shown that pelvic osteotomies produce the greatest narrowing at the pelvic outlet. Little has been said in the obstetrical literature regarding the pelvic outlet. The obstetrical literature has focused on the midpelvis, which is the narrowest plane [10]. Traditional obstetrical teaching has stated that "there is no congenital anomaly or acquired disease which will narrow the tuberosities of the ischium without also narrowing the lower part of the innominate bones. In other words, there can be no serious outlet contraction without commensurate contraction of the midplane" [12]. However, the development of pelvic osteotomies since the time at which this statement was made may have modified its truth.

Little is known regarding the rate of cesarean section after osteotomy. Sutherland and Greenfield [18] stated that all female patients should be warned about the potential need for cesarean section after double innominate osteotomy because of its intentional medialization. Høgh and Manicol [9] noted a 25\% and $100 \%$ cesarean section rate after unilateral and bilateral Chiari osteotomies respectively. The $100 \%$ rate reflects their policy to uniformly adivse cesarean section after bilateral Chiari osteotomies. Rejholec et al. [15] noted a 33\% (20 of 61 births) cesarean section rate after Chiari osteotomy, compared to a $10 \%$ cesarean section rate for the general population in Prague (M. Rejholec, personal communication). Salter [16], Steel [17], and Tönnis et al. [19] did not address this question. Ganz et al. [6] addressed this concern in the design of the periacetabular osteotomy, stating that the shape of the true pelvis with this osteotomy is unaltered. Our study confirms that the periacetabular osteotomy has no effect on birth canal size. Young women having undergone this osteotomy have had successful vaginal deliveries (J. Mast, personal communication).

What little is known regarding cesarean section in postosteotomy patients implicates the Chiari osteotomy as the worst. The Chiari osteotomy affects the transverse diameter more at the inlet and midpelvis than at the outlet. Although other osteotomies effect the transverse diameter of the inlet or midpelvis, the Chiari osteotomy is the one that affects both diameters the most. The average combined change for the inlet and midpelvis transverse diameter by both conventional and CT digital pel- 
vimetry is $-15 \%$ for the Chiari, and $-12 \%,-10 \%$, $-3 \%,-2 \%$, and $0 \%$ for the Sutherland, Steel, Salter, Tönnis, and periacetabular osteotomies respectively. These values more closely fit the known clinical data regarding cesarean section after pelvic osteotomy. Perhaps the combined narrowing of the inlet and midpelvis transverse diameters is the clinically relevant narrowing, with outlet dimensions less important. This will require further clinical investigation.

There are many factors which make a safe vaginal delivery possible [10]. These include the space available in the bony pelvis; fetal size, position, and presentation; fetal head moldability; and the intensity of the powers pushing the fetus. The available space is the only factor potentially alterable by pelvic osteotomy. Because of these multiple factors, most obstetriciens agree that a clinical trial of labor is the gold standard for predicting the success of a vaginal delivery. We advocate pelvimetry in postosteotomy women only when the obstetrician feels it is clinically indicated. Patients should inform their obstetrician if they have had a pelvic osteotomy. Further research will be needed to clarify the incidence of cesarean section in postosteotomy patients. For now, a trial of labor remains the best "test" of cephalopelvic proportion.

Acknowledgements. The authors would like to acknowledge the assistance of Dr. Jeffery Mast in performing the periacetabular osteotomy, and the generosity of Zimmer Corporation (Warsaw, Indiana) in donating the Steinmann pins. We would like to acknowledge the assistance of the X-ray technologist, Ms. Brenda Allen. Finally, the authors would like to acknowledge Dr. Ingrid Nygaar, Department of Obstetrics and Gynecology, University of Michigan, for her assistance in reviewing the manuscript. This study was supported by the Fund for Medical Research and Education, Grant no. 2640, Wayne State University School of Medicine, Detroit, Michigan, USA.

\section{References}

1. Caldwell WE, Maloy HC (1933) Anatomic variations in the female pelvis and their effect in labor with a suggested classification. Am J Obstet Gynecol 26:479-505

2. Chiari K (1974) Medical displacement osteotomy of the pelvis. Clin Orthop 78:55-71

3. Colcher AE, Sussman W (1949) Changing concepts of x-ray pelvimetry. Am J Obstet Gynec 57:510-517
4. De Waal Malefijt MC, Hoogland T, Nielsen HKL (1982) Chiari osteotomy in the treatment of congenital dislocation and subluxation of the hip. J Bone Joint Surg [Am] 64:996

5. Federle MP, Cohen HA, Rosewein MF, Brant-Zowadoki MN, Conn CE (1982) Pelvimetry by digital radiograph: a low-dose examination. Radiology 143:733-735

6. Ganz R, Klaue K, Vinh T, Mast JW (1988) A new periacetabular osteotomy for the treatment of hip dysplasias. Technique and preliminary results. Clin Orthop 232:26-36

7. Gimovsky ML, Willard K, Neglio M, Howard T, Zerne S (1985) X-ray pelvimetry in breech protocol: a comparison of digital radiography and conventional methods. Am J Obstet Gynecol 153:887-888

8. Greulich WW, Thoms H (1944) The growth and development of the pelvis of individual girls before, during, and after puberty. Yale J Biol Med 17:91-97

9. Høgh J, Manicol MF (1987) The Chiari pelvic osteotomy. A long term review of clinical and radiographic results. J Bone Joint Surg [Br] 69:365-373

10. Langer A, Kennedy K (1981) The normal pelvis. In: Iffy L, Kaminetzky $\mathbf{H}$ (eds) Principles and practice of obstetrics and perinatology. Wiley, New York, pp 733-745

11. Lotz H, Ekelund L, Hietala SO, Erikson L, Wiklund DE, Wickman G (1987) Low dose pelvimetry with biplane digital radiography. Acta Radiol 28:577-580

12. Mengert WG (1948) Estimation of pelvic capacity. JAMA 138: 169-175

13. Meschron I (1958) Normal radiographic anatomy. Saunders, Philadelphia, $\mathrm{p} 734$

14. Pettit AV, Garland LH, Dunn RD (1936) Correlation between the shape of the female pelvis and the clinical course of labor. West J Surg Obstet Gynecol 44:1-20

15. Rejholec M, Stryhal F, Rybka V, Popelka S (1990) Chiari osteotomy of the pelvis: a long term study. J Pediatr Orthop 10: $21-27$

16. Salter RB (1961) Innominate osteotomy in the treatment of congenital dislocation and subluxation of the hip. $J$ Bone Joint Surg [Br] 43:510-539

17. Steel HH (1973) Triple osteotomy of the innominate bone. J Bone Joint Surg [Am] 55:343-350

18. Sutherland DH, Greenfield R (1977) Double innominate osteotomy. J Bone Joint Surg [Am] 59:1082-1091

19. Tönnis D, Behrens K, Tscharani F (1981) A modified technique of the triple pelvic osteotomy: early results. J Pediatr Orthop 1:241-249

20. Wedge JH, Salter RB (1974) Innominate osteotomy: its role in the arrest of secondary degenerative arthritis of the hip in the adult. Clin Orthop 98:214-224

21. Winkelman W (1984) The narrowing of the bony pelvic cavity (birth canal) by the different osteotomies of the pelvis. Arch Orthop Trauma Surg 102:159-162 